\title{
Diagnostic utility of S100A1 expression in renal cell neoplasms: an immunohistochemical and quantitative RT-PCR study
}

\author{
Paolo Cossu Roccaํ, Matteo Brunelli², Stefano Gobbo ${ }^{2}$, Albino Eccher ${ }^{2}$, Emma Bragantini², \\ Maria M Mina ${ }^{2}$, Vincenzo Ficarra ${ }^{3}$, Filiberto Zattoni ${ }^{4}$, Alberto Zamò ${ }^{2}$, Maurizio Pea ${ }^{2}$, \\ Aldo Scarpa ${ }^{2}$, Marco Chilosi ${ }^{2}$, Fabio Menestrina ${ }^{2}$, Franco Bonetti ${ }^{2}$, John N Eble ${ }^{5}$ \\ and Guido Martignoni ${ }^{2}$
}

${ }^{1}$ Department of Pathology, University of Sassari, Sassari, Italy; ${ }^{2}$ Department of Pathology, University of Verona, Verona, Italy; ${ }^{3}$ Department of Urology and Surgical Sciences, Urology Clinic, University of Padova, Padova, Italy; ${ }^{4}$ Department of Urology, University of Verona, Verona, Italy and ${ }^{5}$ Department of Pathology and Laboratory Medicine, Indiana University School of Medicine, Indianapolis, IN, USA

\begin{abstract}
S100A1 is a calcium-binding protein, which has been recently found in renal cell neoplasms. We evaluated the diagnostic utility of immunohistochemical detection of S100A1 in 164 renal cell neoplasms. Forty-one clear cell, 32 papillary, and 51 chromophobe renal cell carcinomas, and 40 oncocytomas, 164 samples of normal renal parenchyma adjacent to the tumors and 13 fetal kidneys were analyzed. The levels of S100A1 mRNA detected by quantitative RT-PCR analysis of frozen tissues from seven clear cell, five papillary, and six chromophobe renal cell carcinomas, four oncocytomas, and nine samples of normal renal tissues adjacent to neoplasms were compared with the immunohistochemical detection of protein expression. Clear cell and papillary renal cell carcinomas showed positive reactions for S100A1 in 30 out of 41 tumors $(73 \%)$ and in 30 out of 32 (94\%) tumors, respectively. Thirty-seven renal oncocytomas out of 40 (93\%) were positive for S100A1, whereas 48 of 51 (94\%) chromophobe renal cell carcinomas were negative. S100A1 protein was detected in all samples of unaffected and fetal kidneys. S100A1 mRNA was detected by RT-PCR in all normal kidneys and renal cell neoplasms, although at very different levels. Statistical analyses comparing the different expression of S100A1 in clear cell and chromophobe renal cell carcinomas observed by immunohistochemical and RT-PCR methods showed significant values $(P<0.001)$, such as when comparing by both techniques the different levels of S100A1 expression in chromophobe renal cell carcinomas and oncocytomas $(P<0.001)$. Our study shows that $S 100 \mathrm{A1}$ protein is expressed in oncocytomas, clear cell and papillary renal cell carcinomas but not in chromophobe renal cell carcinomas. Its immunodetection is potentially useful for the differential diagnosis between chromophobe renal cell carcinoma and oncocytoma. Further, S100A1 protein expression is constantly detected in the normal parenchyma of the adult and fetal kidney.
\end{abstract}

Modern Pathology (2007) 20, 722-728; doi:10.1038/modpathol.3800828; published online 4 May 2007

Keywords: S100A1; chromophobe renal cell carcinoma; oncocytoma

Renal cell neoplasms comprise several distinct clinicopathologic entities with therapeutic and prognostic differences. ${ }^{1-5}$ Oncocytomas are benign tumors and chromophobe renal cell carcinomas appear more frequently to be cured by surgery than clear cell and papillary renal cell carcinomas.

Correspondence: Dr G Martignoni, MD, Anatomia Patologica, Università di Verona, Strada Le Grazie n. 8, Verona 37100, Italy. E-mails: guidomart@yahoo.com; guido.martignoni@univr.it

Received 27 February 2007; revised 12 April 2007; accepted 16 April 2007; published online 4 May 2007
A certain degree of morphologic overlap may exist among these neoplasms ${ }^{6}$ and the distinctive histopathological features cannot always be fully appreciated. This problem is expected to increase because of the more frequent use of needle biopsies to diagnose small renal masses. ${ }^{7}$ Immunohistochemical analysis is becoming more frequently useful to narrow the differential diagnosis or to arrive at a definitive diagnosis. ${ }^{8-10}$ Numerous immunohistochemical markers have been proposed for the subclassification of renal cell carcinomas, including 'RCC marker', CD10, and vimentin for clear cell renal cell carcinomas, c-kit 
for chromophobe renal cell carcinomas, and cytokeratin 7 and alpha-methyl-acyl-CoA racemase for papillary renal cell carcinomas. ${ }^{8,9,11,12}$

Parvalbumin, a calcium-binding protein, has been demonstrated to be a useful marker in distinguishing oncocytoma and chromophobe renal cell carcinoma, from clear cell and papillary renal cell carcinomas. ${ }^{11-15}$ S100A1 is another calcium-binding protein of the EF-hand family, the mRNA for which has been recently found in renal cell neoplasms by RT-PCR analysis. ${ }^{16-18}$ In this study, we evaluated the expression and the diagnostic utility of S100A1 in a large series of renal cell neoplasms, using a monoclonal antibody, and compared both S100A 1 protein and mRNA levels in oncocytomas, clear cell, papillary, and chromophobe renal cell carcinomas.

\section{Materials and methods}

One hundred sixty-four renal cell neoplasms were used for the immunohistochemical study, including 41 clear cell, 32 papillary, and 51 chromophobe renal cell carcinomas and 40 oncocytomas. All tumors were retrieved from the files of the Departments of Pathology of the Universities of Sassari and Verona, Italy. The diagnoses were reviewed according to the WHO 2004 Classification of Tumors of the Urinary System and Male Genital Organs, ${ }^{6}$ and clear and papillary renal cell carcinomas were graded according to the morphologic parameters proposed by Fuhrman et al. ${ }^{19}$ The resected specimens containing the tumors had been fixed with buffered formalin and paraffin-embedded. Hale's colloidal iron stain was performed on all of the tumors.

The immunohistochemical reaction with antibody to S100A1 was evaluated in all non-neoplastic kidney tissues from the kidneys bearing the tumors and in 13 fetal kidneys.

We also performed quantitative RT-PCR to detect S100A1 mRNA expression in four oncocytomas, and six chromophobe, seven clear cell and five papillary renal cell carcinomas and in nine frozen samples of normal kidney tissue, adjacent to renal neoplasms. These specimens were obtained from renal parenchyma adjacent to clear cell (six cases) and chromophobe renal cell carcinomas, and a renal oncocytoma.

\section{Immunohistochemistry}

For all formalin-fixed and paraffin-embedded tumors, serial $5 \mu \mathrm{m}$ sections were stained with hematoxylin and eosin, with Hale's colloidal iron technique or immunostained with an antibody recognizing S100A1 protein (Monoclonal mouse Anti Human S100A1, Clone DAK 100A1/1; dilution 1:50, Lab Vision, Fremont, CA, USA). Immunoreactions were developed using a non-biotin, highly sensitive system (Envision peroxidase detection system, DAKO, Carpinteria, CA, USA) preventing possible false-positive staining owing to endogenous biotin present in the tissue.

S100A1 was evaluated as the percentage of positively stained neoplastic cells in a selected tumor section of each case of clear cell or papillary renal cell carcinoma and oncocytoma and in at least two different sections of tumor from each case of chromophobe renal cell carcinoma. The extent of immunoreactivity was categorized as focal $(\leq 10 \%$ positively reacting neoplastic cells), moderate (from 10 to $50 \%$ positively reacting neoplastic cells), and diffuse ( $>50 \%$ positively reacting neoplastic cells). Cytoplasmic and/or nuclear staining was considered positive; S100A1 expression was considered negative in tumors completely lacking positive reactions.

External positive controls were provided by five samples of skeletal muscle, three samples of myocardium and 10 reactive lymph nodes.

\section{Quantitative RT-PCR Analysis of mRNA Expression}

Total RNA was extracted with the RNeasy Kit (QIAGEN, Valencia, CA, USA) from frozen tumor samples and, where available, from normal renal tissue as control.

Oligonucleotide primers were: S100A1, GATGCC CAGAAGGATGTGGAT and AGCCACAAGCACCA CATAC; glyceraldehyde-3-phosphate dehydrogenase $(G A P D)$ ATCATCAGCAATGCCTCCT and GGAC TGTGGTCATGAGTCCT.

cDNA was synthesized from $1 \mu \mathrm{g}$ of total RNA with the First Strand cDNA Synthesis Kit (AMV) (Roche Diagnostic, Mannheim, Germany).

Real-time analysis was performed on an ABI Prism 7000 SDS (Applied Biosystems, Foster City, CA, USA) using the SYBR Green PCR Master Mix (Applied Biosystems). Each assay included a notemplate control and cDNA template equivalent to 20 ng of total RNA (in triplicate). The expression levels of $S 100 A 1$ were calculated by relative quantification using GAPD transcript levels for normalization.

Data were analyzed as indicated in the User Bulletin no. 2 (Applied Biosystems).

\section{Statistical Analysis}

The Pearson $\chi^{2}$ analysis was used to compare S100A1 immunoexpression in clear cell vs chromophobe renal cell carcinomas and renal oncocytomas vs chromophobe renal cell carcinomas (significant value: $P<0.05$ ).

SigmaPlot Student's $t$-test was used to compare relative expression levels (fold-change) of S100A1 mRNA obtained by quantitative RT-PCR.

\section{Results}

\section{Morphological Findings}

Clear cell renal cell carcinomas showed nuclear grade 1 in six tumors, grade 2 in 11 tumors, grade 3 
in 17 tumors, and grade 4 in seven cases. Papillary renal cell carcinomas showed nuclear grade 2 in 17 tumors and grade 3 in 15 tumors. Chromophobe renal cell carcinomas included 48 examples of the classic type (Figure 1a) and three of the eosinophilic variant. Oncocytomas displayed a solid-alveolar pattern (Figure 1b) in 38 cases and a tubulo-cystic pattern in two cases.

All chromophobe renal cell carcinomas stained positively with Hale's colloidal iron, whereas there was no diffuse cytoplasmic staining in oncocytomas. Clear cell and papillary renal cell carcinomas showed only focal and dust-like granular or luminal and coarsely granular staining.

\section{Immunohistochemical Findings}

S100A1 immunostaining was observed in 30 of 41 clear cell renal cell carcinomas (73\%); six showed focal positivity, whereas 24 displayed an immunoreactivity ranging from moderate (12 cases) to diffuse (12 cases) expression. Five of the 11 negative cases (45\%) showed a tubulo-cystic growth pattern, whereas 21 out of $30(70 \%)$ S100A1-positive clear cell renal cell carcinomas exhibited a solid-alveolar architecture. Antibody to S100A1 stained 21/24 (88\%) high-grade (grade 3-4) vs 9/17 (52\%) lowgrade (grade 1-2) clear cell renal cell carcinomas.

S100A1 was detected immunohistochemically in 30 of 32 papillary renal cell carcinomas (94\%), six showing focal, 12 moderate, and 12 diffuse immunoreactivity.

Forty-eight of the 51 chromophobe renal cell carcinomas (94\%) showed no reaction with antibody to S100A1 (Figure 1c). Although we tested at least two different sections for each tumor, and up to five sections of larger neoplasms, these tumors did not show even focal S100A1 expression. Only three chromophobe renal cell carcinomas $(6 \%)$ were positive, two classic variant showing scattered S100A1 immunoreactive cells and an eosinophilic variant with nucleo-cytoplasmic staining in about $40 \%$ of the neoplastic cells.

Thirty-seven of 40 renal oncocytomas (93\%), including the two with the tubulo-cystic growth pattern, gave positive reactions with antibody to S100A1. Most of them showed both cytoplasmic and nuclear moderate to strong immunostaining (Figure $1 \mathrm{~d})$. Of the 37 positive tumors, four $(11 \%)$ showed focal expression, 17 (46\%) moderate expression, and $16(43 \%)$ diffuse expression of S100A1. In the oncocytomas with a pattern of moderate expression the S100A1 staining showed an alternation between positive and negative areas in the same tumor. Further examination of additional sections of tumors from the negative cases confirmed the absence of even focal immunoreactivity.

We found significant differences in S100A1 immunoexpression between clear cell and chromophobe renal cell carcinomas $(P<0.001)$ and between chromophobe renal cell carcinomas and oncocytomas $(P<0.001)$.

S100A1 was detected in all the samples of nonneoplastic renal tissue from the kidneys harboring the tumors. The reactions were moderate to strong in both the nuclei and the cytoplasm of the cells lining proximal tubules, loops of Henle, and collecting ducts. Variable and focal immunostaining was also seen in the cells lining distal convoluted tubules and in Bowman's capsules. The other glomerular components were negative (Figure 1e).

S100A1 was expressed in normal fetal kidney, staining exclusively proximal tubules in all the 13 cases (Figure 1f).

Immunohistochemical S100A1 expression data are summarized in Table 1.

External positive controls showed diffuse immunoreactivity in all skeletal muscle and myocardium tissues and specific cytoplasmic immunostain in follicular dendritic cells of reactive lymph node specimens.

\section{Quantitative RT-PCR Analysis of mRNA Expression}

S100A1 mRNA was detected in all nine normal kidneys and 22 renal epithelial neoplasms, although at very different levels (Figure 2). Tumor samples were compared considering the expression levels of normal kidney as baseline. Using this reference, clear cell renal cell carcinomas expressed 2.9-fold less S100A1 mRNA than normal kidney, chromophobe renal cell carcinomas 7.8-fold less than reference, oncocytomas 1.4-fold more than reference, papillary renal cell carcinomas sixfold more than reference. The cycle threshold differences $\left(\Delta C_{\mathrm{t}}\right)$ between the reference gene (GAPD) and the test gene (S100A1) were much lower for chromophobe renal cell carcinomas (range -2.13 to -0.3 ) than for oncocytomas (range 1.08-3.09) and normal kidneys (range 0.8-2.36). These values are indicative of RNA levels of S100A1 that are on average 11.47-fold higher (range 2.14- to 37.27-fold) in oncocytomas than in chromophobe renal cell carcinomas.

Clear cell renal cell carcinomas overexpressed S100A1 mRNA in comparison with chromophobe renal cell carcinomas $(P<0.001)$. Comparison between chromophobe renal cell carcinomas and oncocytomas showed that oncocytomas expressed on average 11 times more S100A1 mRNA than chromophobe renal cell carcinomas. These differences were highly significant $(P<0.001)$.

Normal kidneys showed RNA levels on average 7.78-fold higher than chromophobe renal cell carcinomas.

All nine samples of normal renal parenchyma, five papillary renal cell carcinomas, and five renal oncocytomas with both immunohistochemical and quantitative RT-PCR analyses showed agreement between the high levels of S100A1 mRNA and detection of the protein by immunohistochemistry. 


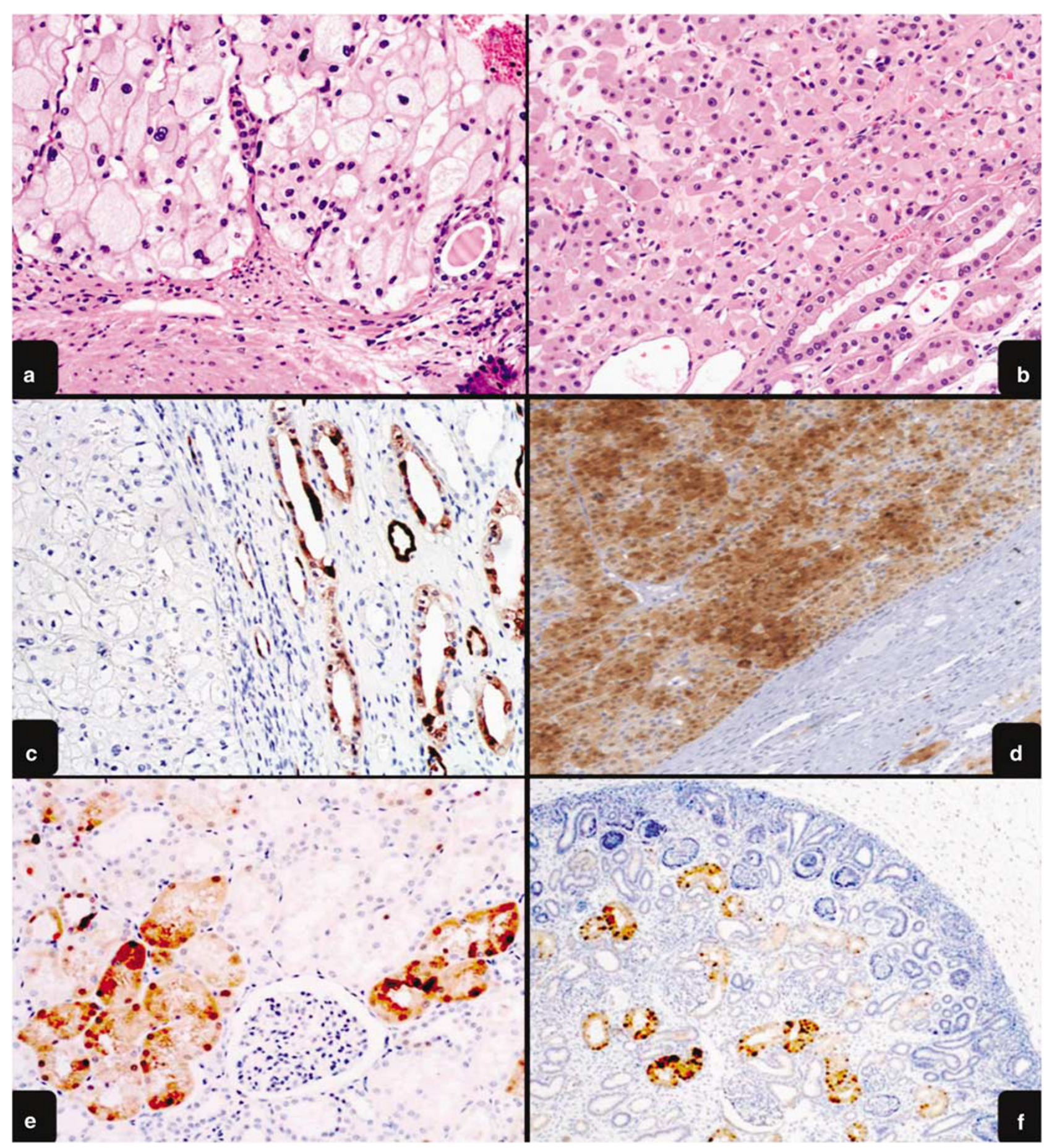

Figure 1 Chromophobe renal cell carcinoma, classic type (a); renal oncocytoma (b); absence of S100A1 immunoexpression in chromophobe renal cell carcinoma (c); diffuse S100A1 expression in renal oncocytoma showing a moderate to strong cytoplasmic and nuclear immunostaining (d); S100A1 immunoreactivity in both nuclei and cytoplasm of the cells lining proximal tubules, Henle loops, and variable and focal stain in distal convoluted tubules. Glomerular components were negative (e); S100A1 expression in the proximal tubules of the normal fetal kidney (f).

All six chromophobe renal cell carcinomas with low levels of $\mathrm{S} 100$ mRNA expression did not contain immunohistochemically detectable S100A1. The clear cell renal cell carcinomas with low level (five cases) and high level (2 cases) mRNA expression had immunohistochemically detectable S100A1.

\section{Discussion}

Current options for the treatment of renal cell neoplasms include radical nephrectomy, nephronsparing surgery, and minimally invasive approaches such as cryo- and radiofrequency ablation. ${ }^{20-24}$ In 
Table 1 S100A1 immunoexpression in renal cell neoplasms

\begin{tabular}{lcc}
\hline Histotype & $\begin{array}{c}\text { No. of } \\
\text { cases }\end{array}$ & $\begin{array}{c}\text { S100A1 } \\
\text { immunoexpression- } \\
\text { positive cases }\end{array}$ \\
\hline Clear cell RCC & 41 & $30(73 \%)$ \\
Papillary RCC & 32 & $30(94 \%)$ \\
Chromophobe RCC & 51 & $3(6 \%)$ \\
Oncocytoma & 40 & $37(93 \%)$ \\
\hline
\end{tabular}

the context of a surgical sparing approach, a preoperative diagnosis by needle-core biopsy is needed to guide management decisions. ${ }^{7,10,25}$ However, the diagnostically specific morphological features of tumors may not be appreciable in small samples and immunohistochemical analysis may be needed to support a definitive diagnosis. ${ }^{8,9}$

Among calcium-binding proteins, the diagnostic utility of parvalbumin has already been demonstrated in distinguishing oncocytoma and chromophobe renal cell carcinoma from clear cell and papillary renal cell carcinomas. ${ }^{11,15}$ Another calcium-binding protein, S100A1, has been recently found in renal cell neoplasms. This protein is a member of the S100 family, the largest subgroup of the EF-hand proteins, which consists of several members that display amino-acid sequence homology ranging from 25 to $65 \% .{ }^{26}$ Thirteen of their genes are clustered on the chromosome 1q21, whereas the others are located on different chromosomes. ${ }^{27}$ Recent investigations have emphasized the potential diagnostic and oncogenetic role of S100 proteins in a variety of tumors. ${ }^{28-34}$

In this study, we found that S100A1 protein is expressed in renal oncocytomas, and in clear cell and papillary renal cell carcinomas but not in chromophobe renal cell carcinomas. We found significant statistical differences between S100A1 immunoexpression in clear cell and chromophobe renal cell carcinomas $(P<0.001)$, which suggests that S100A1 could be a useful tool in their differential diagnosis. Most papillary renal cell carcinomas stained with S100A1 and constantly showed high levels of S100A1 mRNA expression.

The potential utility of S100A1 immunodetection is strongest in the differential diagnosis between chromophobe renal cell carcinoma and oncocytoma. Ninety-four percent of chromophobe renal cell carcinomas were immunohistochemically negative for S100A1, whereas $93 \%$ of the oncocytomas, including both tumors with the tubulo-cystic pattern, were positive with most of them showing moderate to strong immunostaining.

The three chromophobe renal cell carcinomas with neoplastic cells reacting positively for S100A1 antibody also stained positively with Hale's colloidal iron stain.

Among the oncocytomas studied by quantitative RT-PCR analysis, the tumor with the lowest level of

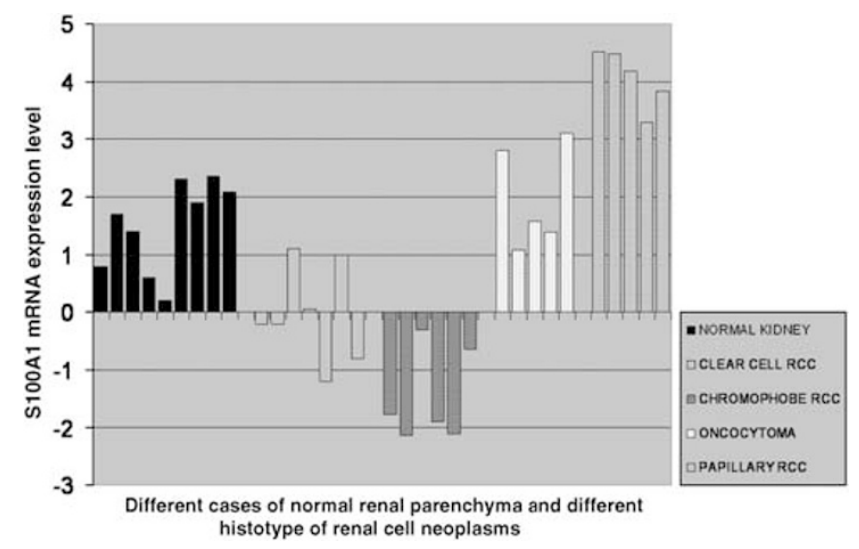

Figure 2 S100A1 mRNA expression levels in normal renal parenchyma and different types of renal cell neoplasms: levels were detected in all nine normal kidneys and 22 renal epithelial neoplasms, although at very different levels. Focus that mRNA levels of S100A1 are on average 11.47-fold higher (range 2.14- to 37.27 -fold) in oncocytomas than in chromophobe renal cell carcinomas.

S100A1 mRNA expression was one of the three oncocytomas negative for S100A1 by immunohistochemistry. This parallels the observation that chromophobe renal cell carcinoma, in which the level of S100A1 mRNA expression is extremely low, showed immunohistochemical negativity for S100A1. Lin et $a l^{17}$ reported the immunohistochemical detection of S100 protein in $87 \%(13 / 15)$ of oncocytomas, with strong and diffuse staining in $60 \%$ of cases, whereas only one $(6 \%)$ of 16 chromophobe renal cell carcinomas showed focal positivity. They used a rabbit polyclonal antibody for S100 protein that has been shown to react with both human and cow S100 protein, with a stronger reaction to $\mathrm{S} 100 \mathrm{~B}$, but a weak reaction to S100A1 and S100A6. ${ }^{17}$ In our study, we used a monoclonal mouse antihuman antibody specifically recognizing S100A1 protein.

In our study, S100A1 mRNA was detected in all 22 renal cell neoplasms by quantitative RT-PCR analysis, although at very different levels. These differences were significant $(P<0.001)$. Li et a ${ }^{18}$ reported an high percentage of S100A1 gene expression profile by RT-PCR in papillary renal cell carcinomas $(11 / 15,73 \%)$, in renal oncocytomas $(7 / 8,87 \%)$ but a low percentage was found in clear cell renal cell carcinomas $(2 / 15,13 \%)$ and negative expression in chromophobe renal cell carcinomas $(0 / 7,0 \%)$. Lin et al studied the S100A1 mRNA expression measured by microarray gene profiling in 14 renal oncocytomas and 14 chromophobe renal cell carcinomas. Comparison between chromophobe renal cell carcinomas and oncocytomas showed that oncocytoma expressed on average 11 times more S100A1 mRNA than chromophobe renal cell carcinomas. ${ }^{17}$

Wide variation of mRNA expression for clear cell renal cell carcinomas may be due to the more heterogeneity of these renal neoplasms.

Renal parenchyma from the kidneys bearing the tumors always displayed cytoplasmic and/or a 
nuclear immunostaining for S100A1 in the cells lining proximal tubules, loops of Henle, collecting ducts, and Bowman's capsule, whereas S100A1 was selectively expressed in the proximal tubules of the normal fetal parenchyma of the kidney. According with the finding of S100A1 immunoexpression in normal parenchyma of adult kidney, quantitative RT-PCR analysis showed the presence of specific S100A1 mRNA in frozen samples of non-neoplastic adult renal tissue in all nine tested cases. These results are in agreement with those obtained by Lin et $a l^{17}$ but in contrast with those by Teratani et $a l^{16}$ and $\mathrm{Li}$ et $a l^{18}$ The absence of S100A1 mRNA detection reported by Teratani et $a l^{16}$ is probably due to some differences in the primer, ${ }^{16}$ whereas we cannot comment on the results of $\mathrm{Li}$ et al because the sequence of the primer was not reported in that study.

In conclusion, we evaluated the expression of S100A1 in renal cell neoplasms with an immunohistochemical study, and verified our results by a quantitative RT-PCR analysis and demonstrated the potential usefulness of the monoclonal antihuman S100A1 antibody in the differential diagnosis among renal cell neoplasms, particularly in the differential diagnosis of chromophobe renal cell carcinoma vs renal oncocytoma.

\section{Acknowledgements}

Fondazione Cassa di Risparmio di Verona; Diagnostica molecolare in oncologia; Ministero Istruzione e Ricerca; Banco di Sardegna. This work was presented in part at the 93rd annual meeting of the US and Canadian Academy of Pathology, February 2004.

\section{References}

1 Cheville JC, Lohse CM, Zincke H, et al. Comparisons of outcome and prognostic features among histologic subtypes of renal cell carcinoma. Am J Surg Pathol 2003;27:612-624.

2 Moch H, Gasser T, Amin MB, et al. Prognostic utility of the recently recommended histologic classification and revised TNM staging system of renal cell carcinoma: a Swiss experience with 588 tumors. Cancer 2000;89:604-614.

3 Amin MB, Amin MB, Tamboli $\mathrm{P}$, et al. Prognostic impact of histologic subtyping of adult renal epithelial neoplasms: an experience of 405 cases. Am J Surg Pathol 2002;26:281-291.

4 Ficarra V, Martignoni G, Galfano A, et al. Prognostic role of the histologic subtypes of renal cell carcinoma after slide revision. Eur Urol 2006;50:786-794.

5 Ficarra V, Martignoni G, Lohse C, et al. External validation of the Mayo Clinic Stage, Size, Grade and Necrosis (SSIGN) score to predict cancer specific survival using a European series of conventional renal cell carcinoma. J Urol 2006;175:1235-1239.
6 Eble JN, Sauter G, Epstein JI, et al. WHO: Tumours of the Urinary System and Male Genital Organs. IARC Press: Lyon, 2004.

7 Volpe A, Jewett MA. The natural history of small renal masses. Nat Clin Pract Urol 2005;2:384-390.

8 Zhou M, Roma A, Magi-Galluzzi C. The usefulness of immunohistochemical markers in the differential diagnosis of renal neoplasms. Clin Lab Med 2005;25:247-257.

9 Skinnider BF, Amin MB. An immunohistochemical approach to the differential diagnosis of renal tumors. Semin Diagn Pathol 2005;22:51-68.

10 Barocas DA, Mathew S, Delpizzo JJ, et al. Renal cell carcinoma sub-typing by histopathology and fluorescence in situ hybridization on a needle-biopsy specimen. BJU Int 2007;99:290-295.

11 Martignoni G, Pea M, Chilosi M, et al. Parvalbumin is constantly expressed in chromophobe renal carcinoma. Mod Pathol 2001;14:760-767.

12 Martignoni G, Pea M, Brunelli M, et al. CD10 is expressed in a subset of chromophobe renal cell carcinomas. Mod Pathol 2004;17:1455-1463.

13 Young AN, Amin MB, Moreno CS, et al. Expression profiling of renal epithelial neoplasms: a method for tumor classification and discovery of diagnostic molecular markers. Am J Pathol 2001;158: 1639-1651.

14 Young AN, de Oliveira Salles PG, Lim SD, et al. Beta defensin-1, parvalbumin, and vimentin: a panel of diagnostic immunohistochemical markers for renal tumors derived from gene expression profiling studies using cDNA microarrays. Am J Surg Pathol 2003;27:199-205.

15 Adley BP, Papavero V, Sugimura J, et al. Diagnostic value of cytokeratin 7 and parvalbumin in differentiating chromophobe renal cell carcinoma from renal oncocytoma. Anal Quant Cytol Histol 2006;28: 228-236.

16 Teratani T, Watanabe T, Kuwahara F, et al. Induced transcriptional expression of calcium-binding protein S100A1 and S100A10 genes in human renal cell carcinoma. Cancer Lett 2002;175:71-77.

17 Lin F, Yang W, Betten M, et al. Expression of S-100 protein in renal cell neoplasms. Hum Pathol 2006;37: 462-470.

18 Li G, Gentil-Perret A, Lambert C, et al. S100A1 and KIT gene expressions in common subtypes of renal tumours. Eur J Surg Oncol 2005;31:299-303.

19 Fuhrman SA, Lasky LC, Limas C. Prognostic significance of morphologic parameters in renal cell carcinoma. Am J Surg Pathol 1982;6:655-663.

20 Schwartz BF, Rewcastle JC, Powell T, et al. Cryoablation of small peripheral renal masses: a retrospective analysis. Urology 2006;68:14-18.

21 Cambio AJ, Evans CP. Management approaches to small renal tumours. BJU Int 2006;97:456-460.

22 Varkarakis IM, Allaf ME, Inagaki T, et al. Percutaneous radio frequency ablation of renal masses: results at a 2-year mean followup. J Urol 2005;174: 456-460.

23 Gervais DA, McGovern FJ, Arellano RS, et al. Renal cell carcinoma: clinical experience and technical success with radio-frequency ablation of 42 tumors. Radiology 2003;226:417-424.

24 Pavlovich CP, Walther MM, Choyke PL, et al. Percutaneous radio frequency ablation of small renal tumors: initial results. J Urol 2002;167:10-15. 
25 Jaff A, Molinie V, Mellot F, et al. Evaluation of imagingguided fine-needle percutaneous biopsy of renal masses. Eur Radiol 2005;15:1721-1726.

26 Schafer BW, Heizmann CW. The S100 family of EF-hand calcium-binding proteins: functions and pathology. Trends Biochem Sci 1996;21:134-140.

27 Donato R. S100: a multigenic family of calciummodulated proteins of the EF-hand type with intracellular and extracellular functional roles. Int J Biochem Cell Biol 2001;33:637-668.

28 Boni R, Burg G, Doguoglu A, et al. Immunohistochemical localization of the $\mathrm{Ca}^{2+}$ binding S100 proteins in normal human skin and melanocytic lesions. Br J Dermatol 1997;137:39-43.

29 Camby I, Lefranc F, Titeca G, et al. Differential expression of S100 calcium-binding proteins characterizes distinct clinical entities in both WHO grade II and III astrocytic tumours. Neuropathol Appl Neurobiol 2000;26:76-90.
30 Hancq S, Salmon I, Brotchi J, et al. Detection of S100B, S100A6 and galectin-3 ligands in meningiomas as markers of aggressiveness. Int J Oncol 2004;25: 1233-1240.

31 Ilg EC, Schafer BW, Heizmann CW. Expression pattern of S100 calcium-binding proteins in human tumors. Int J Cancer 1996;68:325-332.

32 Ji J, Zhao L, Wang X, et al. Differential expression of S100 gene family in human esophageal squamous cell carcinoma. J Cancer Res Clin Oncol 2004;130: $480-486$

33 Kanamori T, Takakura K, Mandai M, et al. Increased expression of calcium-binding protein S100 in human uterine smooth muscle tumours. Mol Hum Reprod 2004;10:735-742.

34 Smith SL, Gugger M, Hoban P, et al. S100A2 is strongly expressed in airway basal cells, preneoplastic bronchial lesions and primary non-small cell lung carcinomas. Br J Cancer 2004;91:1515-1524. 